\title{
Percolation Concept: Polymer-Filler Gel Formation, Electrical Conductivity and Dynamic Electrical Properties of Carbon-Black-Filled Rubbers
}

\author{
Luděk Karásek, Bohumil Meissner*, Shigeo Asai, and Masao Sumita \\ Department of Organic and Polymeric Materials, Tokyo Institute of Technology, \\ 2-12-1 Ookayama, Meguro-ku, Tokyo 152, Japan \\ * Department of Polymers, \\ Prague Institute of Chemical Technology, \\ Technická 5, Prague-6, Czech Republic \\ (Received May 15, 1995)
}

\begin{abstract}
This paper reports results on comparison of polymer-filler gel formation measurements and electrical properties of carbon black filled styrene butadiene rubber (SBR) composites. Electrical conductivity $(\sigma)$ of compounds with different filler concentration has been measured, and dielectric constant $\left(\varepsilon^{\prime}\right)$, dielectric loss $\left(\varepsilon^{\prime \prime}\right)$ and dissipation factor (tan $\delta$ ) have been investigated at frequency range from $1 \mathrm{kHz}$ to $13 \mathrm{MHz}$. It has been found that these systems follow percolation type model. Different electrical percolation thresholds of the composites have been found for different types of carbon black. Carbon blacks with the highest specific surface area reach the percolation threshold with the least fraction of carbon black loading. The electrical percolation threshold was found to be in a very good agreement with the filler concentration which is necessary for the coherent rubber-filler gel formation.
\end{abstract}

KEY WORDS Rubber-Carbon Black Composites / Electrical Conductivity / Dynamic Electrical Properties / Percolation / Polymer-Filler Gel Formation /

In general, the electrical properties of polymers allow their application as insulating materials. However, extensive work has been carried out to make polymers conductive by incorporating particulate fillers. It has been recognized that carbon black plays a dominant role in the electrical properties of filled polymers. ${ }^{1,2} \mathrm{~A}$ variety of electrical measurements have been carried out on carbon black loaded elastomers. ${ }^{3-12}$

The electrical conduction process in carbon blackpolymer composites is complicated and dependent on a large number of parameters, mainly on filler concentration. In addition to the amount of loading, carbon black particle size and structure, filler-matrix interactions, and processing techniques are key factors in determining the electrical properties.

For the case of low filler concentration, the carbon black particles are isolated to such extent that the resistance is large and dielectric constant small. The conductivity increases dractically at a certain concentration of the filler as conductive component, reaching the so-called percolation threshold. It is a consequence of the appearance of the first conducting path. Filler agglomerates reach a size which makes the possibility for them to touch each other. At high enough loading, carbon particles form structures which are in contact throughout the sample.

Partial insolubilization of polymers brought about by the addition of fine-particle fillers is ascribed to the adsorption, from bulk, of some polymer chains on the filler particle surface. In the rubber technology field the filler-insolubilized polymer is usually referred to as bound rubber. In compounds of unsaturated rubbers with fineparticle carbon blacks, the filler particles together with the polymer chains adsorbed on them very often form a coherent three-dimensional structure which only swells and is not disintegrated by the solvent-so called polymer-filler gel. In the region of lower filler concen- trations the gelation may not be complete and the filler bound polymer (and filler particles as well) may be partially or totally dispersed by the solvent. At high enough filler concentration, all filler particles are fixed in the polymer-filler gel and no filler particle can be dispersed by the solvent. The fraction of solventdispersed filler particles $\left(W_{\text {disp }}\right)$, the filler concentration in the gel point $\left(c_{\mathrm{gp}}\right)$, and the critical concentration of filler for coherent gel formation $\left(c_{\mathrm{coh}}\right)$ can be evaluated experimentally. ${ }^{13-15}$

The aim of this work is to investigate systematically the effect of type and quantity of carbon black filler on both electrical conductivities and dielectric properties of SBR-carbon black composites, and compare these observations with the phenomenon of the rubber-filler gel formation.

\section{EXPERIMENTAL}

\section{Materials}

Styrene Butadiene Rubber (SBR). Kralex 1500, produced by the Kaučuk factory (Kralupy n. V., Czech Republic). The unmasticated polymer which does not contain gel had a limiting viscosity number (toluene, $\left.30^{\circ} \mathrm{C}\right) 2.44 \mathrm{dL} \mathrm{g}^{-1}$. The molar mass averages $M_{w}$ and $M_{n}$ were evaluated by GPC measurements- $M_{w}=262.7$ $\mathrm{kg} \mathrm{mol}^{-1}$ and $M_{n}=73.0 \mathrm{~kg} \mathrm{~mol}^{-1}$. The value of $M_{w} /$ $M_{n}=3.60$.

Carbon Blacks. Four types of commercially available carbon blacks without any treatment were used in this study-ISAF, FEF (trade marks Nigros I and Nigros F, respectively, producer DEZA Valašské Meziříčí, Czech Republic), HAF (trade mark IRB 6, producer J. M. Huber, U.S.A.), and lamp carbon black-La (trade mark Durex O, producer Degussa, Germany). Relevant analytical data of these carbon blacks are summarized in Table I. 
Table I. Analytical properties of carbon blacks

\begin{tabular}{lcc}
\hline Carbon black & $\begin{array}{c}\text { Surface area } \\
\text { CTAB } / \mathrm{m}^{2} \mathrm{~g}^{-1}\end{array}$ & DBPA \\
\cline { 3 - 3 } & 86.3 & 104.5 \\
ISAF & 66.4 & 100.1 \\
HAF & 45.2 & 95.4 \\
FEF & 20.4 & 99.8 \\
La & & \\
\hline
\end{tabular}

\section{Preparing Samples}

SBR-carbon black compounds with varying filler concentration were prepared as follows. Approximately $5 \mathrm{~g}$ of rubber cutted into small pieces were placed in a Petri dish and dissolved in $200 \mathrm{ml}$ of benzene. Carbon black was added to the rubber solution and the solvent was evaporated. The film of rubber and carbon black which had arisen after evaporation of benzene was processed on a cold two-roll mill. Care was taken to ensure a good dispersion of the filler in the elastomer. After mixing the compounds were compression molded for 1 hour at $145^{\circ} \mathrm{C}$ to prepare about $1 \mathrm{~mm}$ thick film samples. Carbon black concentrations in composites are expressed in phr (parts per hundred parts of rubber).

\section{Evaluation of Electrical Properties}

The electrical conductivity and the dynamic electrical properties were measured through the vertical thickness of the thin specimen. Silver paste was used to ensure a good contact of the sample surface with copper electrodes. The electrical conductivity of the samples varied over the range from $10^{-16} \mathrm{~S} \mathrm{~cm}^{-1}$ to $10^{-3} \mathrm{~S} \mathrm{~cm}^{-1}$. Low conductivity samples were measured using a KEITHLEY 487 Picoammeter, while high conductivity samples were measured by means of a TOA digital meter model DMM-120A. AC-conductance measurements were made on Hewlett-Packard 4192A LF Impedance Analyser. From these measurements dielectric constant $\left(\varepsilon^{\prime}\right)$, dielectric loss $\left(\varepsilon^{\prime \prime}\right)$, and dissipation factor $(\tan \delta)$ were calculated. The conductivities and dynamic electrical properties were measured at $20^{\circ} \mathrm{C}$.

\section{Polymer-Filler Gel Formation Measurement}

Small samples of known mass (about $0.5 \mathrm{~g}$ ) were placed in weighed pouches made of polyamide monofilament fabric and put into $200 \mathrm{ccm}$ bottles. The non-gel part of the sample (i.e., free-unbound rubber and filler particles with adsorbed polymer, if any) was extracted by adding dry toluene $(100 \mathrm{ccm})$. The solvent was changed 3 times during 5 days. After extraction the pouch contained only the coherent polymer-filler gel swollen with toluene. It was dried and weighed and the mass of the polymer-filler gel was obtained by subtracting the mass of the dried pouch fabric. Thereafter the dry rubber-carbon black gel was analysed by TGA to determine the polymer-filler ratio in the gel. Runs were carried out on a Stanton Redcroft TG-750 thermobalance. The instrument with a sample (appr. $20 \mathrm{mg}$ ) was purged with nitrogen for one hour before starting a determination. Then the sample was heated in nitrogen at $20^{\circ} \mathrm{C} \mathrm{min}^{-1}$ up to $750^{\circ} \mathrm{C}$ when the constant weight was achieved. The weight loss corresponds with the polymer decomposition. From these data the fraction of solvent-dispersed filler particles

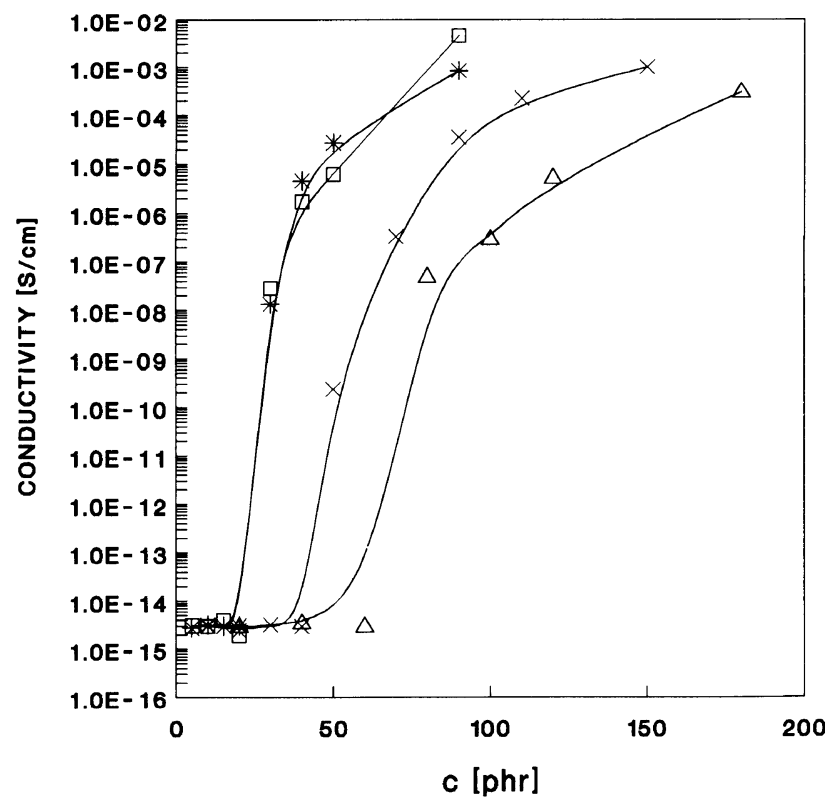

Figure 1. Electrical conductivity of SBR-carbon black composites versus carbon black concentration in phr. Carbon black types: $(*)$ ISAF; ( $\square$ ) HAF; ( $\times$ ) FEF; $(\triangle)$ La.

$\left(W_{\text {disp }}\right)$ was calculated.

Bound rubber and polymer-filler gel formation measurements were described in detail in previous publications. ${ }^{13-15}$

\section{RESULTS AND DISCUSSION}

The results shown in Figure 1 relate to the effect of carbon black concentration on the electrical conductivity of SBR-carbon black (four different types) compounds. The concuctivity increases very sharply after reaching the percolation threshold which strongly depends on the filler type. It is observed, as expected, that the higher specific area of carbon black the smaller fraction of filler is necessary for reaching the percolation threshold.

Recently, models which tries to predict and explain the electrical conductivity of mixtures made of conductive and insulating materials have been reviewed. ${ }^{16}$

One of the most convincing theoretical approach to the calculation of conductivity is in terms of percolation theory. The theory predicts the correlation of the conductivity of composites, $\sigma$, with the volume fraction of the conductive filler

$$
\sigma=\sigma_{0}\left(X-X_{\mathrm{c}}\right)^{\mathrm{s}}
$$

where $\sigma_{0}$ is the conductivity of the filler particles, $X$ the volume fraction of the filler, $X_{\mathrm{c}}$ the volume fraction of the filler at percolation threshold, and $s$ a quantity determining the power of the conductivity increasing above $X_{\mathrm{c}}$. According to the theory a value about $1.5-2.0$ should be expected for the exponent $s$. Such values were found for different systems ${ }^{17}$ and for polymer-carbon black composites as well. ${ }^{18-20}$ The nature of critical exponent $s$ is unique for defined particle geometry. However, for the fractions of filler lower than $X_{\mathrm{c}}$ the experimental data cannot be directly explained by the percolation model.

By plotting the electrical conductivity against the excess of filler concentration above percolation one 
$\left(X-X_{\mathrm{c}}\right)$ using a log-log scale, a system obeying the percolation model should give a straight line. Figure 2 shows such graph for SBR-FEF carbon black composites. The value of slope (exponent $s$ ) is unexpectedly high, $s=7.75$. The exponents $s$ observed for the other SBR-carbon black composites are summarized in Table II. Abo-Hashem and co-workers ${ }^{11}$ found a high value of exponent $s(s=5.4)$ for butyl rubber-SRF carbon black systems as well. The value of $s=3$ accounts for the presence of carbon clusters. The even higher values of exponent $s$ were proposed to be explained due to occluded rubber which is trapped inside the voids of carbon aggregates and which acts as a part of carbon rather than a part of the matrix. ${ }^{11}$ Similar high value of exponent $s$ was reported for polyethylene-graphite composites $^{21}(s=6.27)$ but the authors tried to decrease it by shifting the percolating threshold towards higher filler concentrations.

Electron tunneling is an important mechanism in many processes of solid-state physics and its presence in carbon black composites has been fully documented. ${ }^{1}$ The conductivity of the composite can be described by the behavior of a single tunnel junction. It was proposed ${ }^{21}$ that the validity of the model can be tested by the presence of a linear dependence of electrical conductivity on $X^{-1 / 3}$. The result for SBR-carbon black composites is summarized in Figure 3. As the single tunnel junction model is a rough approximation, the obtained dependences can be fitted with straight lines, so the tunneling conduction mechanism could be considered.

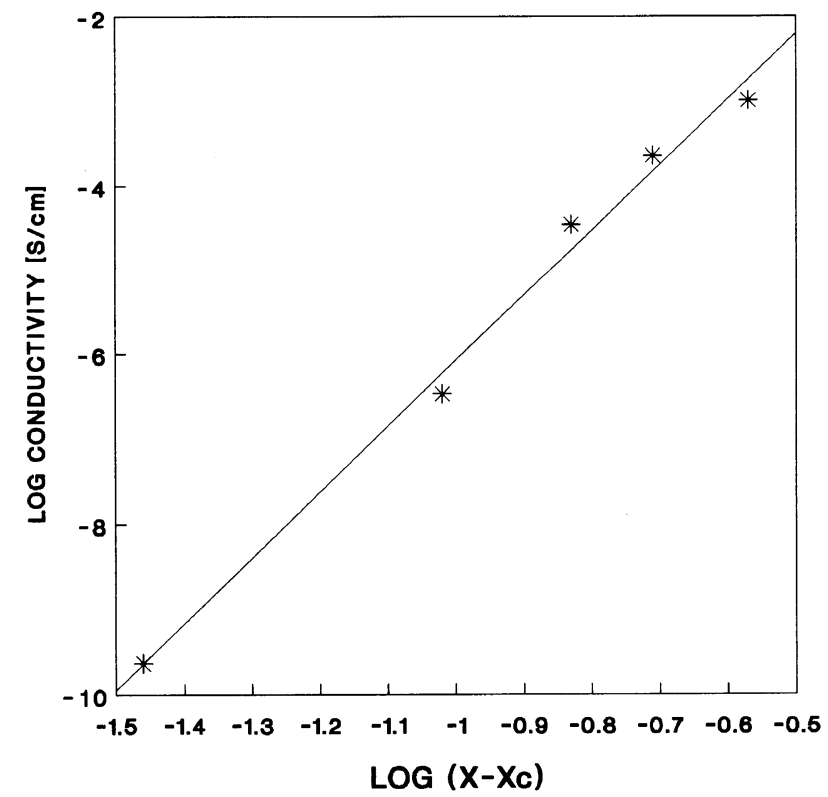

Figure 2. Electrical conductivity as a function of excess concentration $\left(X-X_{\mathrm{c}}\right)$, for SBR-FEF carbon black composites.

Table II. Parameters of the percolation model equation for SBR-carbon black composites

\begin{tabular}{lccc}
\hline Carbon black & $X_{\mathrm{c}}$ & $s$ & $\begin{array}{c}\text { Linear correl. } \\
\text { coefficient }\end{array}$ \\
\hline ISAF & 0.097 & 6.40 & 0.97 \\
HAF & 0.097 & 6.90 & 0.97 \\
FEF & 0.177 & 7.75 & 0.99 \\
La & 0.244 & 6.11 & 0.94 \\
\hline
\end{tabular}

The complex dielectric constant is usually defined by

$$
\varepsilon^{*}=\varepsilon^{\prime}-i \varepsilon^{\prime \prime}
$$

where the real part $\left(\varepsilon^{\prime}\right)$, related to the storage of energy, is commonly known as the dielectric constant; the imaginary part $\left(\varepsilon^{\prime \prime}\right)$, related to the energy loss of the system, is generally called the loss factor. The ratio of the imaginary to the real parts $\left(\varepsilon^{\prime \prime} / \varepsilon^{\prime}\right)$ is the dissipation factor, which represents $\tan \delta$, where $\delta$ is the angle between the voltage and the changing current, i.e., the lag in the displacement current vector due to the presence of the dielectric.

The dependences of the dielectric constant on frequency for SBR-HAF carbon black composites are demonstrated in Figure 4. The dielectric constant of lowfilled polymers (below critical percolation concentration) is almost independent on frequency. Samples with filler

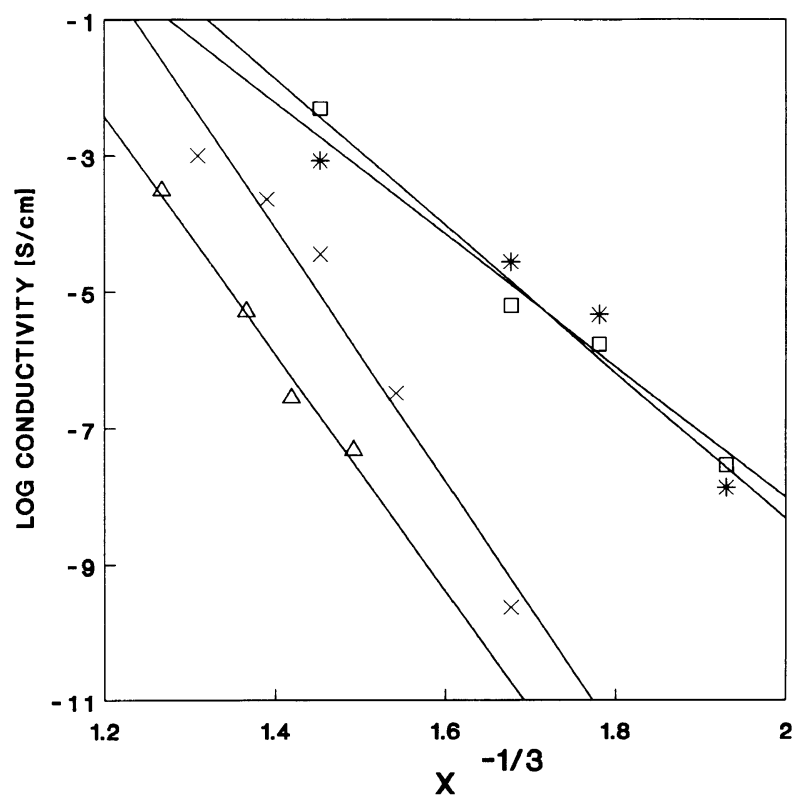

Figure 3. Variation of electrical conductivity of SBR-carbon black composites versus $X^{-1 / 3}$ (see the text). Carbon black types: $(*)$ ISAF; $(\square) \mathrm{HAF} ;(\times) \mathrm{FEF} ;(\triangle) \mathrm{La}$.

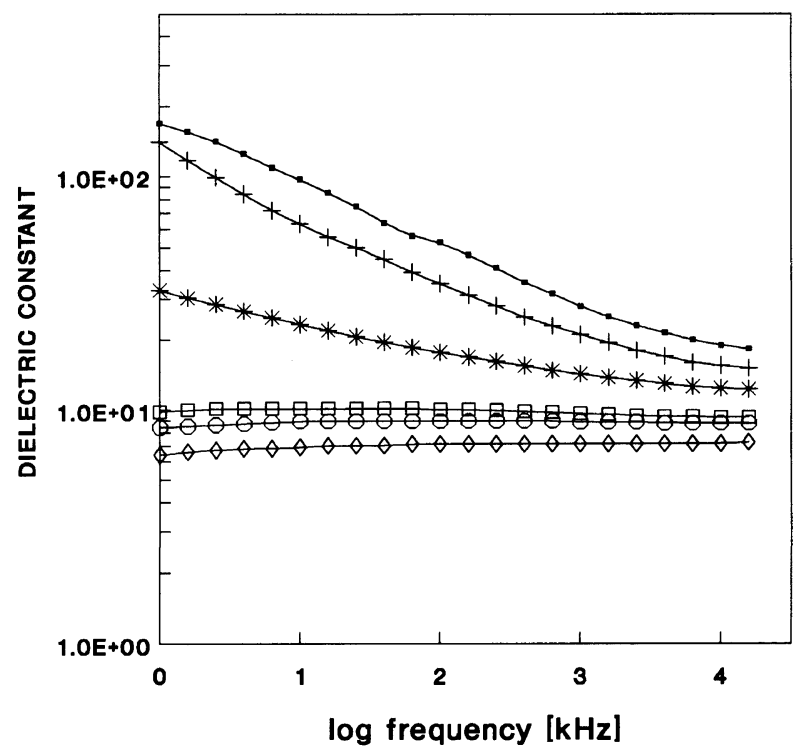

Figure 4. Dielectric constant, $\varepsilon^{\prime}$, of SBR-HAF carbon black composites as a function of frequency. Carbon black concentrations

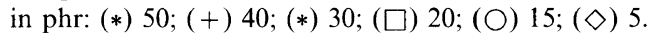


concentration above percolation threshold have decreasing dielectrical constant with increasing frequency. At each frequency, the dielectric constant gradually increases with the filler loading but the rate of change of dielectric constant at any fixed frequency with the filler loading is not uniform.

The dielectric constant increases slowly with the carbon black concentration up to roughly the percolation threshold due to an average reduction of distance between filler aggregates, above the percolation threshold concentration it increases rapidly. Figure 5 shows the dependence of dielectric constant on carbon black concentration, measured at three different frequencies (1, 10 , and $100 \mathrm{kHz}$ ), of SBR-HAF carbon black compounds.

Figure 6 shows the loss factor as a function of frequency of SBR-HAF carbon black composites for

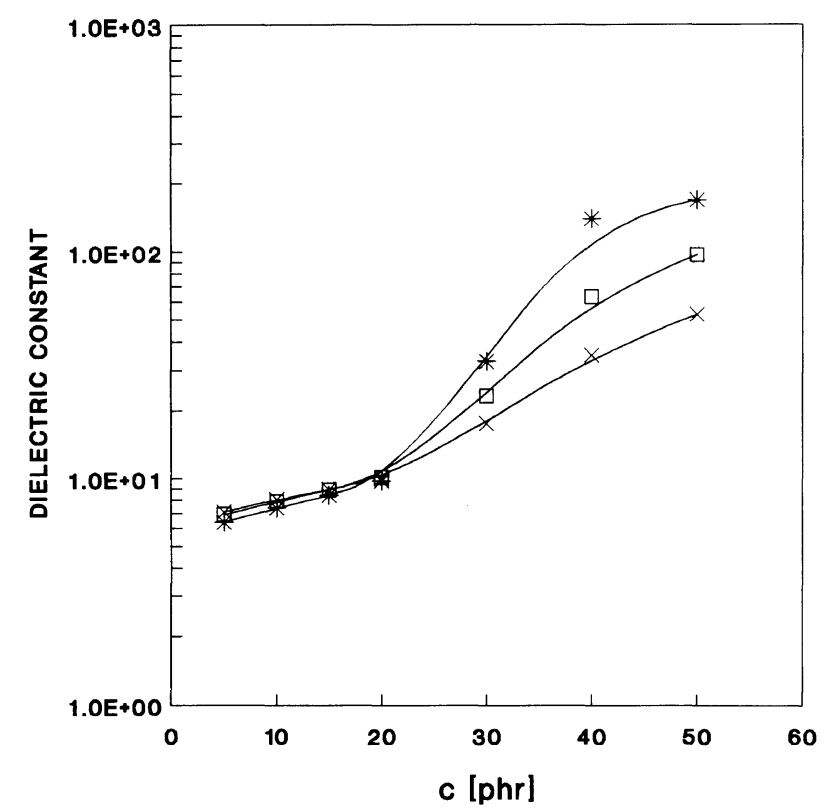

Figure 5. Dependences of dielectric constant, $\varepsilon^{\prime}$, of SBR-HAF carbon black composites on carbon black concentration in phr. Measurement frequencies in $\mathrm{kHz}:(*) 1 ;(\square) 10 ;(\times) 100$.

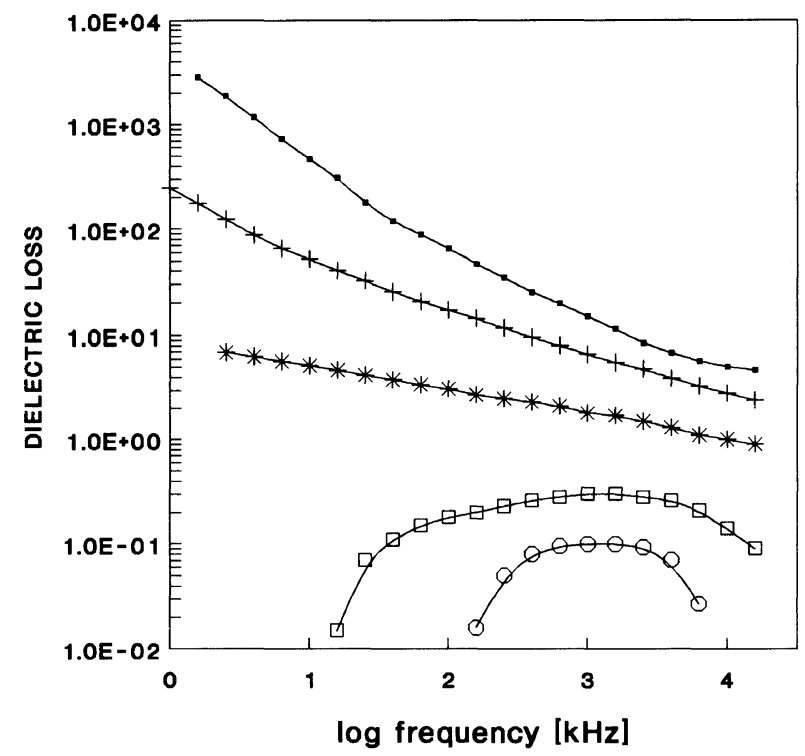

Figure 6. Dielectric loss, $\varepsilon^{\prime \prime}$, of SBR-HAF carbon black composites as a function of frequency. Carbon black concentrations in phr: $(\cdot)$ 50; (+) 40; (*) 30; ( $\square$ ) 20; (○) 15 . filler loading range between 15 and $50 \mathrm{phr}$. A maximum that is observed for the dependences with low filler concentrations disappears above the percolation threshold concentration.

The variations of the dielectric properties with composition are also shown in Figures 7 and 8 . Both the dielectric constant $\varepsilon^{\prime}$ and the dissipation factor $\tan \delta$ increase moderately up to a point in the vicinity of the critical percolation concentration and this slow increase is followed with a faster rate above it. No peak was found at dependences of $\tan \delta$ versus filler loading as it was observed for polyethylene-carbon black systems. ${ }^{18,20-22}$

There are two important values of filler concentration in regards to the polymer-filler gel formation-the filler concentration in the gel point $\left(c_{\mathrm{gp}}\right)$, when first traces of

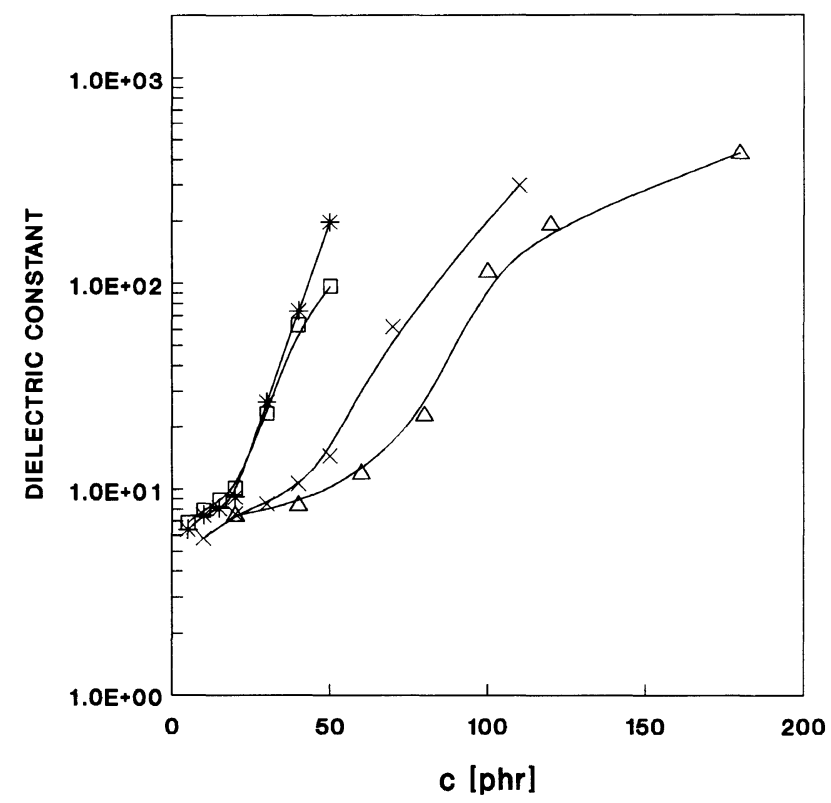

Figure 7. Dielectrical constant, $\varepsilon^{\prime}$, of SBR-carbon black composites versus carbon black concentration in phr (measurement frequency $1 \mathrm{kHz}$ ). Carbon black types: (*) ISAF; $(\square) \mathrm{HAF} ;(\times) \mathrm{FEF} ;(\triangle) \mathrm{La}$.

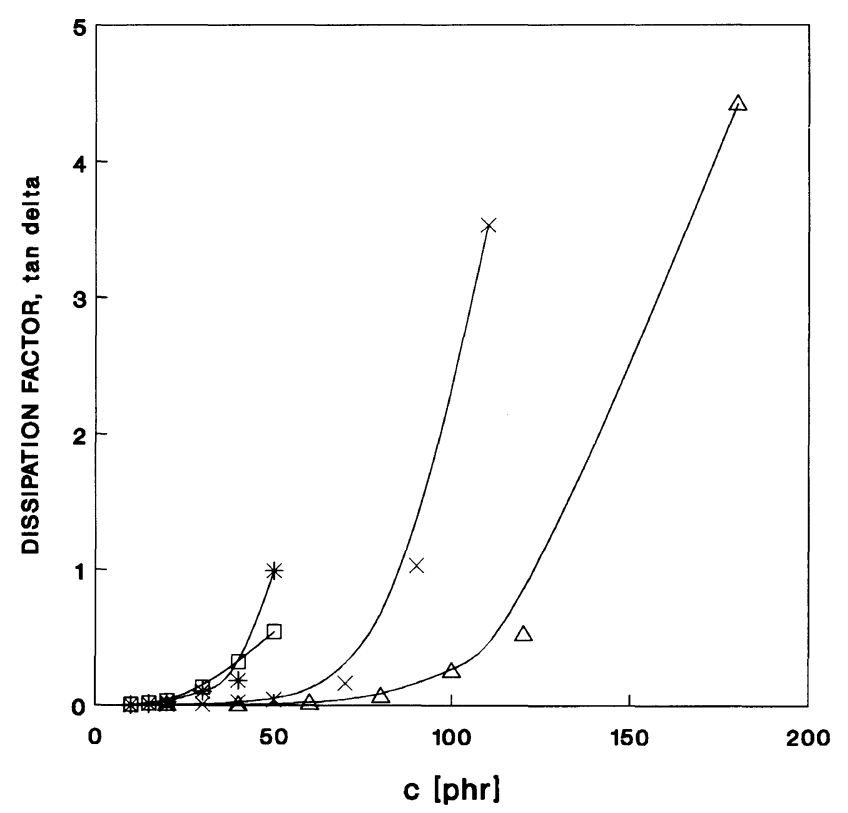

Figure 8. Dissipation factor, $\tan \delta$, of SBR-carbon black composites versus carbon black concentration in phr (measurement frequency $1 \mathrm{MHz}$ ). Carbon black types: $(*)$ ISAF; $(\square) \mathrm{HAF} ;(\times) \mathrm{FEF} ;(\triangle) \mathrm{La}$. 
polymer-filler gel appear, and the critical concentration of filler for coherent gel formation $\left(c_{\mathrm{coh}}\right)$. According to the theory, the fraction of solvent-dispersed filler particles $\left(W_{\text {disp }}\right)$ is seen to decrease rapidly with increasing filler concentration above the gel point. This behavior was observed for both rubber-fume silica compounds ${ }^{13}$ and rubber-carbon black composites. ${ }^{14,15}$ It was found that the value of $c_{\text {coh }}$ is approximately three times higher than the value of $c_{\mathrm{gp}} \cdot{ }^{13}$ At the critical concentration of filler for coherent gel formation $\left(c_{\mathrm{coh}}\right)$, the value of $W_{\mathrm{disp}}$ is equal to zero and all filler particles with the macromolecular chains create the coherent three-dimensional gel structure. This situation can be compared to the

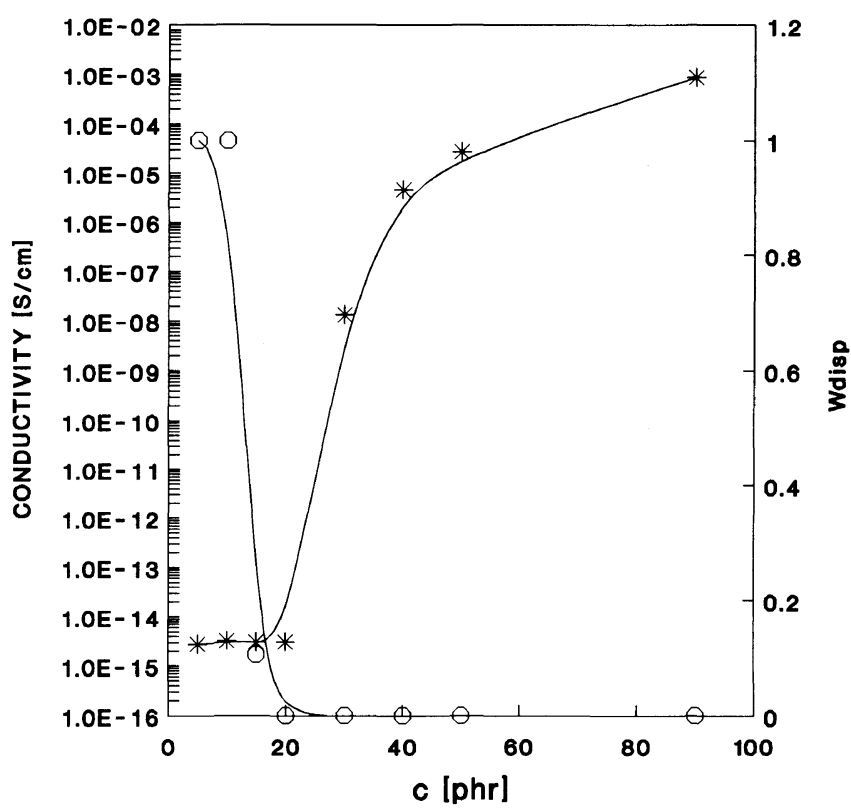

Figure 9. Electrical conductivity and the fraction of solvent-dispersed filler particles, $W_{\text {disp }}$, as a function of filler concentration in phr, for SBR-ISAF carbon black composites. $(*)$ electrical conductivity; $(\bigcirc)$ Wdisp.

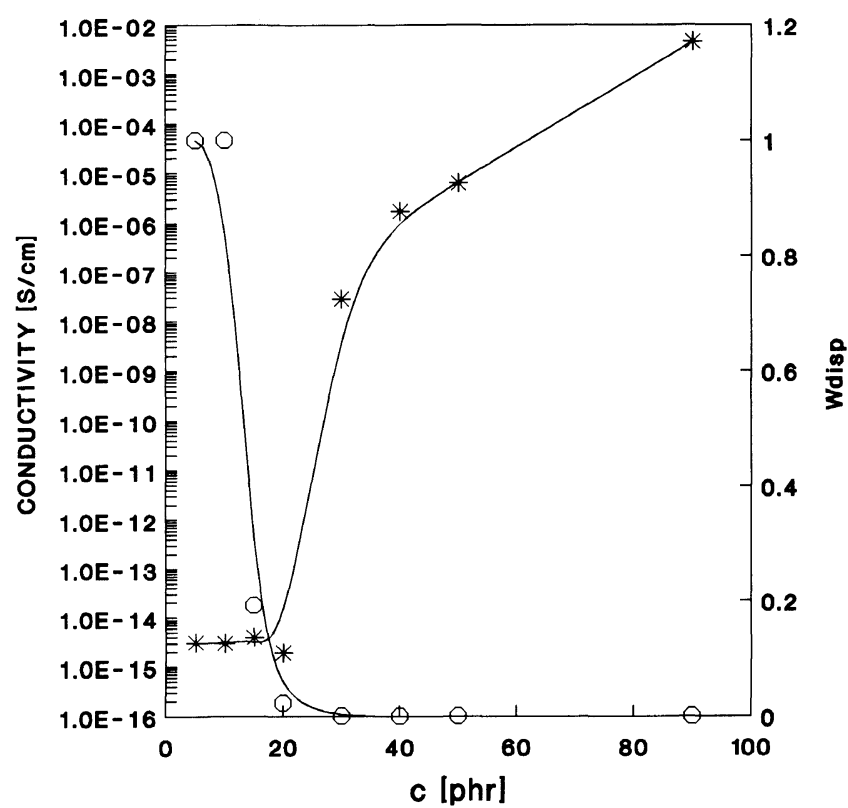

Figure 10. Electrical conductivity and the fraction of solventdispersed filler particles, $W_{\text {disp }}$, as a function of filler concentration in phr, for SBR-HAF carbon black composites. $(*)$ electrical conductivity; $(\bigcirc) W_{\text {disp. }}$. percolation threshold.

The comparison of dependences of electrical conductivities and the fractions of solvent-dispersed filler particles, $W_{\text {disp }}$, on the filler concentration for SBRcarbon black composites is presented in Figures 9-12. It is important to note that these are independent phenomena and that conditions of the filler dispersion in samples are same. There is evident from the figures that the percolation thresholds of electrical conductivities occur at the same filler concentrations when the fractions of solvent-dispersed filler particles achieve zero value or are smaller than 0.05 . It means that the sharp increases of electrical conductivity of SBR-carbon black compo-

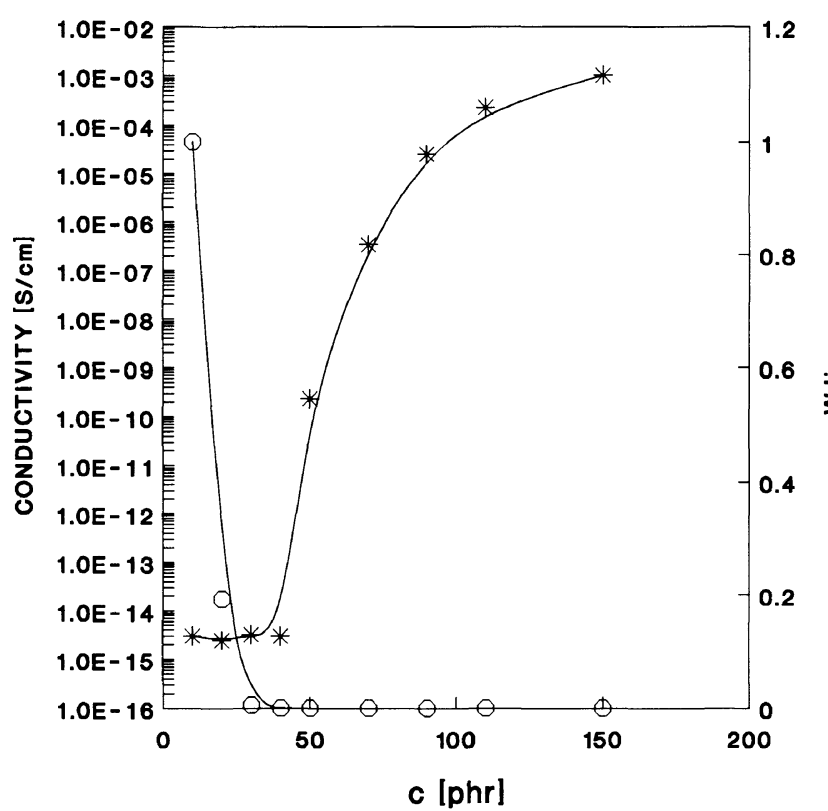

Figure 11. Electrical conductivity and the fraction of solventdispersed filler particles, $W_{\text {disp }}$, as a function of filler concentration in phr, for SBR-FEF carbon black composites. (*) electrical conductivity; (O) $W_{\text {disp }}$.

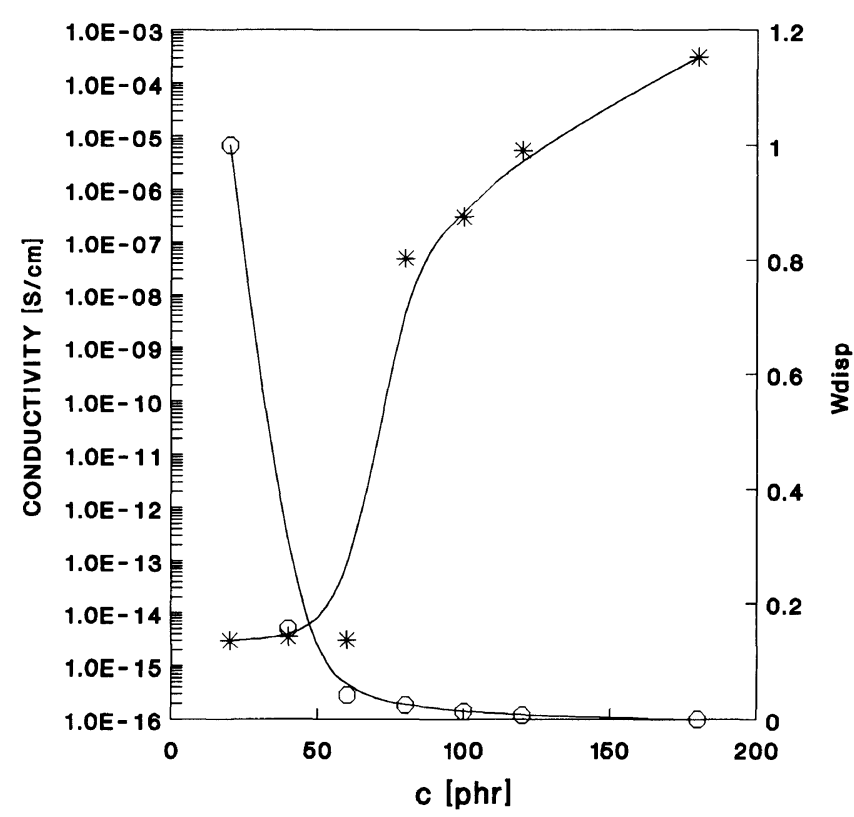

Figure 12. Electrical conductivity and the fraction of solventdispersed filler particles, $W_{\text {disp }}$, as a function of filler concentration in phr, for SBR-La carbon black composites. (*) electrical conductivity; (O) $W_{\text {disp }}$. 
sites occur at the filler concentration region when all filler particles are built into the coherent polymer-filler gel, so also a macroscopic path created by all filler particlespolymer structure from one end of sample to the other is reached.

\section{CONCLUSIONS}

In summary, the different electrical percolation thresholds of the SBR-carbon black composites were found for different species of filler. It was observed that the critical filler concentration decreases with increasing specific surface area of filler.

Percolation theory has been used to explain the insulator-conductor transition occurring in composite systems when the critical concentration $X_{\mathrm{c}}$ is reached. Very high values of exponent $s$ (which correspond with fractal numbers) were found. The electron tunneling mechanism of conduction can be considered.

The dynamic electrical properties of SBR-carbon black compounds were studied over a wide range of frequencies. Carbon blacks with different specific surface area showed different electrical behavior. The percolation threshold is distinct from dependences of dielectric constant and dissipation factor on filler concentration as well. No peak at the dependence of dissipation factor on filler loading was found.

The positions of percolation threshold observed from electrical properties measurements are in a very good agreement with the filler concentrations which are necessary for the coherent rubber-filler gel formation.

Acknowledgments. The work of one of us (L.K.) was supported by a postdoctoral fellowship of the Tokyo Institute of Technology.

\section{REFERENCES}

1. A. I. Medalia, Rubber Chem. Technol., 59, 432 (1986).

2. T. M. Aminabhavi and P. E. Cassidy, Rubber Chem. Technol., 62, 451 (1989).

3. W. F. Verhelst, K. G. Wolthuis, A. Voet, P. Ehrburger, and J. B. Donnet, Rubber Chem. Technol., 50, 735 (1977).

4. A. Voet, Rubber Chem. Technol., 54, 42 (1981).

5. E. M. Cashell, J. M. D. Coey, G. E. Wardell, V. J. McBrierty, and D. C. Douglass, J. Appl. Phys., 52, 1542 (1981).

6. L. C. Burton, K. Hwang, and T. Zhang, Rubber Chem. Technol., 62, 838 (1989).

7. A. I. Eatah, K. N. Abd El-Nour, A. A. Ghani, and A. A. Hashem, Polym. Degradation and Stability, 22, 91 (1988).

8. J. D. Ajayi and C. Hepburn, Plast. Rubber Proc. Appl., 1, 317 (1981).

9. P. Bengtsson, C. Klason, J. Kubát, and D. H. McQueen, J. Phys D: Appl. Phys., 22, 1736 (1989).

10. P. Bengtsson, C. Klason, J. Kubát, and D. H. McQueen, Plast. Rubber Composites. Proccess Appl., 15, 257 (1991).

11. A. Abo-Hashem, H. M. Saad, and A. H. Ashor, Plast. Rubber Composites Process Appl., 21, 125 (1994).

12. K. Miyasaka, K. Watanabe, E. Jojima, H. Aida, M. Sumita, and K. Ishikawa, J. Mater. Sci., 17, 1610 (1982).

13. L. Karásek and B. Meissner, J. Appl. Polym. Sci., 52, 1925 (1994).

14. B. Meissner and L. Karásek, to be published.

15. L. Karásek, $\mathrm{PhD}$ thesis, Prague Institute of Chemical Technology, Czech Republic (1994).

16. F. Lux, J. Mater. Sci., 28, 285 (1993).

17. P. S. Clarke, J. W. Orton, and A. J. Guest, Phys. Rev. B, 18, 1813 (1978).

18. J. Yacubowicz and M. Narkis, Polym. Eng. Sci., 26, 1568 (1986).

19. L. Benguigui, J. Yacubowicz, and M. Narkis, J. Appl. Polym. Sci., Polym. Phys., 25, 127 (1987).

20. J. Yacubowicz, M. Narkis, and L. Benguigui, Polym. Eng. Sci. 28, 1581 (1988)

21. T. A. Azquerra, M. Kulescza, C. S. Cruz, and F. J. Balta-Calleja, Adv. Mater., 2, 597 (1990).

22. J. Yacubowicz, M. Narkis, and L. Benguigui, Polym. Eng. Sci., 30, 459 (1990). 